\title{
Study on Design of Carbon-Credit's Cost Accounting System for Manufacturing Enterprises Problems
}

\author{
Chengzhi Liu, Bolun Liu, Ziang Yang \\ Department of Accounting, Shaoyang University, Hunan, 422000, China
}

\begin{abstract}
As the price of carbon credit gradually reflects the economic value caused by the scarcity of atmospheric environmental capacity, the cost structure in manufacturing enterprises' products will be changed greatly. As an indispensable element of components, carbon credit will become an important cost component of production similar to traditional items as material \& labor cost, etc. Therefore, manufacturing enterprises should reasonably set up its environmental management and cost accounting departments and coordinate the work among related departments; design the information carriers, accounting procedures and analysis indexes for carbon credit cost; strengthen the internal control of its accounting and to set up its accountability center.
\end{abstract}

Keywords-manufacturing enterprises; carbon credit cost accounting; system design.

\section{INTRODUCTION}

Total Emissions Control and quota trade are the worldwide mainstream policy for carbon emission reduction. Therefore, the pressure of carbon credit cost in manufacturing enterprises will become bigger and bigger, the proportion of carbon credit expenditures in production cost will be higher and higher, carbon credit cost will be linked to enterprises' decision-making, the requirements for the fineness and accuracy of the cost accounting of carbon credit will be higher. And then the carbon credit cost accounting in manufacturing enterprises' products should be designed as system engineering so as to ensure the accuracy of accounting. In this paper the organization, information and control system for the carbon credit cost accounting in products are designed respectively.

\section{THE DESIGN OF ORGANIZATION SYSTEM}

In manufacturing enterprises, the accounting of carbon credit's cost in products mainly involves enterprise environment, the cost accounting department and relevant personnel, which form an organizational system for cost accounting. This system should be made up of enterprise's environmental department, cost accounting department and their staff. When enterprises constitute relevant institutions, they should clarify their responsibilities, authorities and main tasks. When they allocate relevant staff, they should clear-out their assignments and post duties, etc.

\section{A. To set up environmental department}

The problems such as the deletion of enterprise environmental (management) department and the delay of environmental disclosure are important factors that affect carbon credit's cost accounting. So firstly enterprises should perfect the systems for their environmental management and information disclosure as soon as possible, they are demanded to set up special department and staff to manage their environment. Secondly, they should design the contents and standards for their environmental disclosure according to the rules and characteristics of their cost accounting, on the basis of meeting the general contents of enterprises' environmental disclosure, combining the requirements of carbon credit's cost accounting in products, and supply more specific, detailed and desirable systematic norms, so as to improve the internal quality of carbon credit's cost accounting. Thirdly, they should reinforce system design and binding force for carbon credit cost accounting. And make unified regulations for the form, time, content and technique for carbon emissions so that the carbon emissions in manufacturing enterprises and the cost information of carbon credit in products will be more comparative and useful in its industry even in the whole country.

\section{B. To set up enterprises' cost department}

Enterprises' cost accounting generally belongs to the financial department, however, some enterprises may set up a special department to account and manage their cost. In manufacturing enterprises especially in large and middlesized enterprises, the accounting and management of cost are important parts in their financial accounting. Which involves the ascription, marketing and allocation of its costs and expenses, and directly affects enterprises' current profits and taxes. At present, enterprises' cost accounting mainly is the accounting of their cost of material and labor and manufacturing, the accounting about carbon credit cost hasn't been carried out. In practical, the expenditure of enterprises' carbon credit cost has directly been handled as period expenses. After the accounting of carbon credit cost has been carried out, the components of cost accounting and management in enterprises will be greatly enriched. Therefore, enterprises should support and guarantee the work at organization and human resources. Namely, setting up a special department to check and manage the cost, which is not only the organization guarantee, but also an important condition to carry out the work. 


\section{To organize and coordinate the carbon-credit's cost accounting in products}

Carbon-credit's cost accounting in manufacturing enterprises' products is a job of great comprehensiveness, which can be finished with the coordination and cooperation of various departments like environment, cost and production department. So to organize different systems to work harmoniously is very important. Usually, enterprises' cost accounting is mainly in the charge of cost department, which plays a leading role in the whole process. At the same time, it needs the assistance and cooperation of various departments.

-Environmental department should supply the data of activity level and the report about carbon emissions monthly.

-The warehousing department should offer in and out records or receipts about raw materials monthly, while the department to keep finished products should offer in and out records or receipts about finished products monthly.

- The production management department should offer statistics of working hours and production schedules.

-The purchasing department should offer account payable receipts the same month.

-The sales department should offer sales statements to make clear monthly sales.

\section{THE DESIGN FOR INFORMATION SYSTEM}

The cost accounting of manufacturing enterprises is an information system which mainly offers the cost information of their products. The design of information system for carbon credits' cost in products is to plan to offer various aspects about products' carbon credit information. Including the design for the carriers of cost accounting, which mainly define the category and format of relevant source documents and detail statements and the relations among them. Secondly, the design for cost accounting handling procedure mainly designs the accumulation and allocation procedures for carbon credits' cost. Scientific handling procedures may have different efficiency and effectiveness. Thirdly, they should design scientific and rational analysis index system.

\section{A. The design of the carriers for cost accounting}

The carriers of cost accounting for products' carbon credit mainly include source documents and accounting ledger. The source documents involved in the process of carbon credits' cost accounting in manufacturing enterprises' products mainly are the source information offered by environmental protection department and assets management department. The cost department can also make internal source documents, so as to meet the need of bookkeeping of cost accounting in products' carbon credit. In the process of cost accounting, enterprises should add general ledger and subsidiary ledger of assets and the general ledger and subsidiary ledger of liability for carbon credit. Both carbon credits' assets and liability account should use the format of amount sum subsidiary ledger. In addition, they also need to add a detailed column for carbon credit to the subsidiary ledger of cost and income account such as the subsidiary ledger of production cost, management cost, manufacturing cost, investment income and grant, etc, to check the cost revenue and expenditure because of the occurrence of carbon credits.

\section{B. The design for cost accounting procedure}

The carbon credits'cost accounting procedure in manufacturing enterprises' products actually is to accumulate and allocate carbon credit's cost. After it is accumulated and allocated a few times, carbon credit s' cost and total cost will finally be gotten. Then we'll introduce the methods to accumulate and allocate carbon credits' cost in the following passage.

The accumulation of cost is to collect, sort and summarize the cost data of products. The assembly summarized the production cost of a product is "the accumulation point of cost" or "cost assembly" in the process of cost accounting. After manufacturing enterprises participate in carbon emissions trading, the carbon emissions generated in the production and operation processes should correspond to the corresponding obligation of delivery to fulfill. As the value of carbon credit existed in the carbon emission trading market objectively, the carbon credit's obligation of delivery in manufacturing enterprises is an actual consumption of value, which is similar to the consumption of materials and labor in production process, should be counted to the production cost. During the production and operation process of manufacturing enterprises, the consumption of carbon credit actually plays an important role in many aspects, for example, some carbon emissions are produced in the process of production , maintenance of production equipment and management, some are produced during the process of non-industrial production. In the process of cost accounting, the consumption about carbon credit should be counted into products' production cost, should be accumulated to cost item. For instance, the consumed cost of carbon credit which is directly helpful to the forming of products should be counted to "the carbon- credit cost" item, while the carbon credit cost generated during the process of maintenance equipment and management should be counted to the "manufacturing cost". It should not be counted to production cost, however, it belongs to period cost, so it should be counted to management cost or selling cost, etc. The carbon credit cost produced during the process of purchasing and building fixed assets and other assets should be counted to neither production cost nor period cost, while counted to "project in process" or other related subjects.

The consumed carbon credit cost which is directly helpful to the production of products should be counted to direct cost according to the corresponding products, be included to "direct material" of various cost of products. However, the cost of a carbon emitter is consumed by several patches of products. For example, the carbon emissions produced by some generic device, it is the cost occurred among various products in the production, should be counted into the cost of various products and should be allocated by an scientific and rational method. If 
manufacturing enterprises use a relatively accurate carbon consumables quota, or the ration of rated consumption of carbon credits, or the ratio of norm cost of materials to allot carbon credits. The concrete formula is:

The allocation rate $=$ the actual consumption of carbon credit (or actual cost) $\div$ the sum of rated consumption of carbon credit in various products (or the sum of norm cost)

The planned carbon credits quantities of a product (cost) $=$ the rated carbon credit s' consumption of the product $\times$ allocation ratio

Besides the above method of allocation, carbon credits can be allocated in other methods. For example, the carbon credit cost generated by the electric power used in common, if we are sure of the working hours that each machine cost to produce a product, it is more reasonable to allocate the cost according to machine-hour. The carbon credit cost generated by auxiliary production department ( the department of power, gas and heat supply), can be allocated in the way of allocating auxiliary production cost, but can not be allocated after combining with the auxiliary production cost, so as to ensure the accuracy and completeness of carbon credit s' cost accounting in a product.

The carbon credit cost in manufacturing enterprises' production process should be counted as the debtor in the account of "production cost" and the subsidiary ledger it belongs to, meanwhile in subsidiary ledger it should be accounted separately as a special column of "carbon credit cost”. In addition, the carbon credit cost in auxiliary department and those in production workshop and administration department for managing and organizing production, should be counted into" production costauxiliary production cost", "manufacturing cost" and" management cost", etc, and counted as the debtor in their subsidiary ledgers. As for the carbon credit used for nonproduction should be counted into other related items.

\section{The design of analysis indexes for products' carbon credit cost}

When enterprises formulate their standard cost, no matter what cost items are calculated, they should define their quantitative criteria and price criteria and calculate the cost standard of the cost item by multiplying the two. No matter what it is, the quantitative criterion or price criterion, it can be a criterion under ideal condition or normal state, enterprises can calculate its ideal standard cost or normal standard cost. The standard consumption of carbon credits in manufacturing enterprises' products is defined by statistical method, industrial engineering method and other technical analysis method. It is the consumption of carbon credit needed to produce unit product under present technical conditions.

The following is a case of standard cost of product carbon credit.
TABLE I. THE STANDARD COST OF CARBON CREDIT IN A PRODUCT

\begin{tabular}{|c|c|c|c|}
\hline \multirow[b]{2}{*}{ standards } & \multicolumn{2}{|c|}{ direct emissions } & \multirow{2}{*}{$\begin{array}{l}\text { Indirect } \\
\text { emission }\end{array}$} \\
\hline & $\begin{array}{c}\text { technological } \\
\text { emission I }\end{array}$ & $\begin{array}{c}\text { technological } \\
\text { emission II }\end{array}$ & \\
\hline $\begin{array}{l}\text { standard } \\
\text { price }\end{array}$ & 45yuan/t & 45yuan/t & 45yuan/t \\
\hline $\begin{array}{l}\text { quantity } \\
\text { standard }\end{array}$ & $0.35 t$ & $0.34 \mathrm{t}$ & $0.26 \mathrm{t}$ \\
\hline $\begin{array}{c}\text { cost } \\
\text { standard }\end{array}$ & 15.75yuan & 15.3yuan & 11.7 \\
\hline $\begin{array}{c}\text { standard } \\
\text { cost of unit } \\
\text { product }\end{array}$ & & 42.75yuan & \\
\hline
\end{tabular}

The standard cost of carbon credit is a target cost, because of various reasons, the actual carbon credits' cost may not accord with the target. There are differences between actual cost and standard cost, which are called standard cost differences of products' carbon credits, or are short for cost differences of carbon credits. The cost differences of carbon credits reflect the actual cost divorces from the predetermined target. To correct the differences, we should analyze the differences and the reasons that caused the differences, so as to adapt some effective measures to correct it.

There are two main reasons that caused the differences: one is its price divorces from standard, the other is its consumption divorces from standard. The former is counted by actual consumption, which is called price differences of carbon credits, while the latter is counted by price, which is called quantitative difference of carbon credit. The price differences are produced during the management and trading of carbon credits, so we should not ask production department to undertake the responsibility, while let the management and trading departments explain it and undertake the corresponding responsibility. There are many reasons why the assets management and transaction department cannot supply carbon credits according to standard cost, Such as, the fluctuation of transaction price in the market, the adjustment of its distribution methods, the change of supply-demand situation in the market and the reasonableness of the operation in its transaction market. The quantity differences of carbon credits is produced during the production, which reflects production department's performance in carbon credits' cost control and in implementing saving energy. There are many reasons to cause the quantitative differences of carbon credits, For instance, negligence in the operation process may cause waste products and materials increased and then make carbon emission increased; workers' operation techniques are improved and then make their working efficiency improved, carbon emissions reduced; the use of new equipment and techniques may reduce the carbon emissions, If enterprises use obsolete machines and equipment or repair and maintain them improperly, carbon emissions will also be increased. Therefore, only by investigation and research can we define who will responsible for the quantitative differences of carbon credits' cost. 


\section{THE DESIGN FOR CONTROL SYSTEM}

\section{A. The internal control of carbon credits' cost accounting in products}

The main contents of internal control of carbon credits' cost accounting in manufacturing enterprises' products are the following: firstly, carbon emissions should be measured under the specific or general mandate of enterprise management level. The key internal control points are the mandate for the measurement and report of carbon emissions. Secondly, the recorded carbon credit cost is real instead of imaginary. The key internal control point is that the accounting of carbon credit cost is based on the detailed statements of carbon emissions and the allocation of carbon credit cost that have been audited. All of the cost of carbon credit reflects in the production cost. The key internal control points are all detailed statements of carbon emissions and the distribution list of carbon credit are numbered in advance and registered on the account. If the carbon credit cost is just in its cost period, it should be recorded in right amount in the proper account. The key internal control points are that the method of cost accounting and distribution of the carbon credit cost should be proper and consistent, and the procedures of enterprises' cost accounting and financial settlement should be proper and consistent. The operator and recorder of carbon credits trading should be mutual independent. The key point of its internal control is operators and recorders' duties should be separated from each other.

\section{B. How to set up and check carbon credits' cost responsibility center}

The cost center of manufacturing enterprises refers to the responsibility center just to produce cost, not to acquire revenue. Usually its operating activities just have effects on the cost fluctuation. These responsibility centers just check its cost control performances. From the characteristics of carbon credits, it is not only manufacturing enterprises' cost item, but also can be used as investment instrument, in theory, it should not be checked as pure cost center, but when checked the reserve and disbursement of enterprises' carbon credits, the check is mainly correspond to the delivery responsibility produced by carbon emissions, so it can be set up and checked as cost center.

In manufacturing enterprises, the setting of cost center for carbon credits should not only combine with the characteristics of carbon emissions but also accord with the various characteristics of production and management. Usually, the units which can organize production and management separately, those whose carbon emissions can be recognized independently and those whose cost control of carbon credits can be checked alone, from factory or department to workshop or team, all can be regarded as responsibility center for carbon credits cost. Meanwhile, the responsibility cost and cost of carbon credits are two concepts that have both connections and discrepancies. The responsibility cost and cost of carbon credits produced in a certain period in manufacturing enterprises should be consistent, but the two have obvious differences, which mainly reflect on the following two aspects: Firstly, the cost of carbon credits is checked according to products, while its responsibility cost is checked through cost center, and it is the controllable cost of each cost center. Secondly, the cost of carbon credits is the compensation for fixing the consumption cost of carbon credits, while the responsibility cost of carbon credits aims to check the completion of energy saving and reducing the cost responsibility of carbon credits, find out the insufficiency and the causes, take steps and then reduce cost. Then we give samples to illustrate the differences between the two kinds of costs.

Let us suppose that a certain manufacturing enterprise produce two kinds of products, A and B. The enterprise has two production departments a and $\mathrm{b}$ and two management departments $\mathrm{c}$ and $\mathrm{d}$, all of them are cost center of carbon credits. All of the cost of carbon credits related to the two kinds of products in a certain month is 51 thousand yuan, the table 11 is a contrast between carbon credits' cost and responsibility cost worked out according to the allocation of carbon credits in the two products and various departments.

TABLE II. A CONTRAST BETWEEN CARBON-CREDIT'S COST AND RESPONSIBILITY COST

\begin{tabular}{|c|c|c|c|c|}
\hline \multicolumn{5}{|c|}{ I . carbon- credit's cost of all products } \\
\hline \multirow{2}{*}{ cost items } & 1000 products A & \multicolumn{2}{|c|}{500 products B } \\
\cline { 2 - 5 } & total cost & unit cost & total cost & unit cost \\
\hline $\begin{array}{c}\text { carbon-credit's } \\
\text { cost }\end{array}$ & 34000 & 34 & 17000 & 34 \\
\hline \multicolumn{3}{|c|}{ II . carbon-credit's responsibility cost in various departments } \\
\hline $\begin{array}{c}\text { cost items } \\
\text { carbon- } \\
\text { credit's } \\
\text { cost }\end{array}$ & 26700 & 15300 & 3400 & 5600 \\
\hline
\end{tabular}

As carbon-credit's cost center has no income, they are just responsible for carbon credit cost, the evaluation and check for it should mainly be put on carbon-credit's responsibility cost. The implementation of responsibility cost and the differences between responsibility cost and the budget will be reflected by compiling responsibility reports about carbon credit and then analyze the causes produced the differences. During the compiling, we should not only pay attention to its real-time and applicability, and try to let the reporting time conform with the time to plan and control production, make the responsibility report meet enterprise various management level and managers' need for the information about carbon emissions and carbon credits' cost expenditure, but also pay attention to the report's correlation and tangibility ,and make sure that the information in the reports is accurate and reliable, and then make need of management of all levels manage the controllable carbon emissions in their responsibility effectively.

The responsibility reports of carbon credit cost center generally include the budgets, actual numbers and differential numbers for various detailed items of controllable cost. The settlement for non-controllable 
carbon credit cost of the department itself can adapt the following two means, one is that to ellipsis all, not to list it, so that the main points are stressed; the other is not to put non-controllable cost into performance report as reference data, so that the managers can get a complete picture of carbon credit's expenditure in a period of time. The cost variance in cost responsibility report for carbon credit is an important symbol to check and evaluate the cost center's work performance. If the actual number is less than the budget, it is called favorable variance, which indicates the savings on carbon credit cost, means the department reduces carbon emissions, and also does great contribution on saving energy and reducing pollutant discharge; if the actual number is larger than the budget, it is called unfavorable variance, which indicates the cost overrun of carbon credit, means that the department increases carbon emissions and needs to save energy and improve the efficiency to protect environment.

\section{ACKNOWLEDGEMENTS}

Project supported by Sociology Science Foundation of Hunan Province, (No: 14YBA344); Project Supported by Scientific Research Fund of Hunan Provincial Education Department (No: 14A130). 